\title{
A Multi-attribute Evaluation Method with Linguistic Values
}

\author{
Chuanhua Zeng ${ }^{1,2}$ Yang $\mathrm{Xu}^{2}$ \\ ${ }^{1}$ School of Transportation and Automotive Engineering, Xihua University, Chengdu 610039, P.R. China \\ ${ }^{2}$ Intelligent Control Development Center, Southwest Jiaotong University, Chengdu 610031, P.R. China
}

\begin{abstract}
An evaluation method with attributes' weights and attributes' values being pure linguistic values is put forward in this paper. The final result is obtained through calculating the linguistic values directly. Based on this method, a weights optimization model and a corresponding algorithm are advanced and applied to evaluate the final result for the technical examination of vehicles in accident, which show the proposed method to be feasible and effective.
\end{abstract}

Keywords: Evaluation, Linguistic values, Weight, Genetic algorithm

\section{Introduction}

Due to fuzziness and uncertainty of the things to be evaluated, the evaluation information in linguistic form is usually given, which results in more concern over the evaluation theory based on linguistic value [1]-[9]. In the current studies, the evaluation theory based on linguistic value can be classified into the following three categories: the first one is based on extension principle [9]; the second one makes direct computations on labels [10]; the last one represents the linguistic information with a pair of values called 2tuple, composed by a linguistic term and a number [8]. Also we can classify these methods of evaluation by the form of attributes weight and attributes evaluation values: the first one is the method with the attributes' weights being certain real numbers and the attribute values being linguistic values, which converts the linguistic value to the real number and calculates the geometric average according to the certain weights [11]-[14]; the second one is the method with the attributes' weights totally being uncertain and the attribute values being linguistic values, which doesn't consider the attributes' weights when aggregating the information, so the method serves well when the attributes' weights can not be easily gotten, but it may lead to wrong evaluation because the uncertain weights can not show us how important the attributes are [15]-[17]; The last one is the method with the attributes' weight and attributes values all being linguistic values [8][12]-[27], which can be fuzzy linguistic method or pure linguistic method. For instance, the OWA employed in reference [19] belongs to the former, and the method adopted in reference [28] serves as an example of the latter, which in fact, still calculates the label of the linguistic values to get the final result. More importantly, Yang $\mathrm{Xu}$ presents a general method for sensory evaluation of industrial products with uncertain information [29]. In fact, all the methods are not actually linguistic values. They get the final results by calculating the real numbers while showing the final result in linguistic values.

Method with attributes' weight and attributes' values being pure linguistic values is introduced in the section 2 of this paper, which gets the final result through calculating the linguistic values directly. Also, a weights optimization model and a corresponding algorithm are given in section 3. Lastly, this method is applied to evaluate the final result for the technical examination of vehicles in accident, which proves feasible.

\section{Linguistic values and its operators}

Let $S=\left\{s_{i} \mid i=0,1, \ldots, t\right\}$ be the set of linguistic values, $s_{i} \in S$ is a linguistic value, and it should satisfy the following characteristics:

1) The set is ordered, i.e. $s_{i}>s_{j}$ if $i>j$;

2) There is the negative operator: $\operatorname{neg}\left(s_{i}\right)=s_{j}$ such that $i+j=t$;

3) There is the maximum operator: $\max \left(s_{i}, s_{j}\right)=s_{i}$ if $s_{i} \geq s_{j}$

4) There is the minimum operator: $\min \left(s_{i}, s_{j}\right)=s_{i}$ if $s_{i} \leq s_{j}$.

Taking the technical examination of vehicles for instance, the set of linguistic values for the result of each examination item can be defined as 
$S=\left\{s_{0}=\right.$ Extremely poor, $S_{1}=$ Very poor, $s_{2}=$ Poor, $s_{3}=$ Medium, $s_{4}=$ Good, $s_{5}=$ Very good, $s_{6}=$ Extremely good $\}$.

Also, the attributes' weight value can be defined as

$$
S^{\prime}=\left\{S_{0}^{\prime}=\text { very low, } S_{1}^{\prime}=\text { low, } S_{2}^{\prime}=\right.\text { medium, }
$$
$s_{3}^{\prime}=$ high, $s_{4}^{\prime}=$ very high $\}$.

For any linguistic variable $s_{i}, s_{j} \in S$, the operator $\oplus$ can be defined as follows:

$$
s_{i} \oplus s_{j}=\operatorname{Min}\left(s_{i}, s_{j}\right) .
$$

For any linguistic variable $s_{i} \in S$ and linguistic weight variable $s_{j}^{\prime} \in S^{\prime}, s_{j}^{\prime} \otimes s_{i}$ can be different in different applications, taking the technical examination of vehicles as an example, the operator $s_{j}^{\prime} \otimes s_{i}$ can be defined as follows:

\begin{tabular}{|c|c|c|c|c|}
\hline$\otimes$ & $\begin{array}{c}\text { Extremel } \\
\text { y poor }\end{array}$ & $\begin{array}{c}\text { Very } \\
\text { poor }\end{array}$ & Poor & Medium \\
\hline Very low & Poor & Poor & Medium & Medium \\
\hline Low & Poor & Poor & Medium & Medium \\
\hline Medium & $\begin{array}{c}\text { Very } \\
\text { poor }\end{array}$ & $\begin{array}{c}\text { Very } \\
\text { poor }\end{array}$ & Poor & Medium \\
\hline High & $\begin{array}{c}\text { Extremel } \\
\text { y poor }\end{array}$ & $\begin{array}{c}\text { Extremel } \\
\text { y poor }\end{array}$ & $\begin{array}{c}\text { Very } \\
\text { poor }\end{array}$ & Medium \\
\hline Very high & $\begin{array}{c}\text { Extremel } \\
\text { y poor }\end{array}$ & $\begin{array}{c}\text { Extremel } \\
\text { y poor }\end{array}$ & $\begin{array}{c}\text { Extremel } \\
\text { y poor }\end{array}$ & Medium \\
\hline
\end{tabular}

\begin{tabular}{|c|c|c|c|}
\hline$\otimes$ & Good & Very good & $\begin{array}{c}\text { Extremely } \\
\text { good }\end{array}$ \\
\hline Very low & Good & Good & Good \\
\hline Low & Good & Good & Good \\
\hline Medium & Good & Good & $\begin{array}{c}\text { Extremely } \\
\text { good }\end{array}$ \\
\hline High & Good & Very good & $\begin{array}{c}\text { Extremely } \\
\text { good }\end{array}$ \\
\hline Very high & Good & Very good & $\begin{array}{c}\text { Extremely } \\
\text { good }\end{array}$ \\
\hline
\end{tabular}

Table1: The definition of $S_{j} \otimes S_{i}$.

Based on the two operators defined above, the linguistic aggregation operator can be defined as follows:

Definition 1 Let LIA be the linguistic aggregation operator, $L I A: S^{n} \rightarrow S$, i.e.

$$
\begin{aligned}
& \operatorname{LIA}_{W}\left(p_{1}, p_{2}, \ldots, p_{n}\right)= \\
& \left(w_{1} \otimes p_{1}\right) \oplus\left(w_{2} \otimes p_{2}\right) \oplus \ldots \oplus\left(w_{n} \otimes p_{n}\right), \quad \text { in } \\
& \text { which } W=\left(w_{1}, w_{2}, \ldots, w_{n}\right), \quad w_{i} \in S^{\prime} \text { is the }
\end{aligned}
$$

linguistic weights vector, and $\left(p_{1}, p_{2}, \ldots, p_{n}\right)$, $p_{j} \in S$ are evaluation results for all sub-items.

\section{The weights optimization model and the corresponding algorithm}

Generally, the weight for each attribute is given by evaluators, which is subjective. So how to get the right weights is discussed by researchers, and some objective methods for weights setting are advanced, such as the principal component analysis method, the Entropic method, the multi-objective maximum distance method, and the method based on rough set theory. But these methods are all based on the weights being real number, and there is no study based on the weights being linguistic values. Thus an linguistic weights optimization model and the corresponding algorithm are presented as follows:

\subsection{The discrepancy of results}

To show the difference between the results given by evaluators and the result calculated based on the method, the discrepancy of results is defined as follows:

Definition 2 Suppose $s_{i} \in S$ is the evaluation result given by the evaluator in historical cases, and $s_{j} \in S$ is the result calculated based on the method, the function for discrepancy of results is $P: S \times S \longrightarrow R$.

So the discrepancy of results is expressed in real number, and its value reflects the discrepancy between the results given by evaluators and the result calculated based on the method.

We can get the discrepancy of results from evaluators. Taking the technical examination of vehicles as an example, the discrepancy of results is showed in the following table:

\begin{tabular}{|c|c|c|c|c|}
\hline$S_{j}$ & $\begin{array}{c}\text { Extremely } \\
\text { poor }\end{array}$ & $\begin{array}{c}\text { Very } \\
\text { poor }\end{array}$ & Poor & Medium \\
\hline $\begin{array}{c}\text { Extremely } \\
\text { poor }\end{array}$ & 0 & 20 & 40 & 80 \\
\hline Very poor & 20 & 0 & 20 & 40 \\
\hline Poor & 40 & 20 & 0 & 20 \\
\hline Medium & 80 & 40 & 20 & 0 \\
\hline Good & 160 & 80 & 40 & 20 \\
\hline Very good & 320 & 160 & 80 & 40 \\
\hline $\begin{array}{c}\text { Extremely } \\
\text { good }\end{array}$ & 640 & 320 & 160 & 80 \\
\hline
\end{tabular}




\begin{tabular}{|c|c|c|c|}
\hline$S_{j}$ & Good & Very good & Extremely good \\
\hline $\begin{array}{c}\text { Extremely } \\
\text { poor }\end{array}$ & 160 & 320 & 640 \\
\hline Very poor & 80 & 160 & 320 \\
\hline Poor & 40 & 80 & 160 \\
\hline Medium & 20 & 40 & 80 \\
\hline Good & 0 & 20 & 40 \\
\hline Very good & 20 & 0 & 20 \\
\hline $\begin{array}{c}\text { Extremely } \\
\text { good }\end{array}$ & 40 & 20 & 0 \\
\hline
\end{tabular}

Table2: the discrepancy of results.

\subsection{The weights optimization model}

Suppose $M$ is the historical cases base, for any case $c_{k} \in M$, the evaluator gives the evaluation results $\left(p_{k 1}, p_{k 2}, \ldots, p_{k m}\right)$ ( $p_{k j}$ is corresponding to the $j$ th item of $C_{k}$ ), also the evaluator gives the synthetical result $q_{k}$ for this case.

Suppose the evaluator's subjective weights are $\left(w_{1}^{\prime}, w_{2}^{\prime}, \ldots, w_{m}^{\prime}\right)$, the optimization weights are $\left(w_{1}, w_{2}, \ldots, w_{m}\right)$, then the weights optimization model is

$\operatorname{Min}(Z)=$

$$
\begin{aligned}
& (1-\lambda) \sum_{k=1}^{n} P\left(q_{k}, \operatorname{LIA}_{\left(w_{1}, w_{2}, \ldots, w_{m}\right)}\left(p_{k 1}, p_{k 2}, \ldots, p_{k m}\right)\right) \\
& +\lambda \sum_{i=1}^{m} P\left(w_{i}^{\prime}, w_{i}\right)
\end{aligned}
$$

Here $\sum_{i=1}^{m} P\left(w_{i}^{\prime}, w_{i}\right)$ is the discrepancy between the subjective weights and the optimization weights, so the function $P^{\prime}\left(w_{i}^{\prime}, w_{i}\right)$ for the weights values need to be defined; $\lambda$ is the rate of weights discrepancy, $0 \leq \lambda \leq 1$.

\subsection{Solving the model with Genetic Algorithm}

We can solve the weights optimization model with Genetic Algorithm, and the Fitness Function is just the Target Function of model, which aims at getting the minimum value of model. So the best gene is the one whose Target Function value is minimum. According to the Tournament Selection method this one is chosen as the new gene for the next generation. Through generations, we can get the best gene as well as the best solution for this model. To get the solution for this model by employing the Genetic Algorithm, we need to ascertain how to code the genes, Also we need to set the length for each chromosome $L$ for each chromosome, the scale $M$ for the initial group, the Crossover Probability $p_{c}$, the Mutation Probability $p_{m}$, and the total number of generations $T$.

\section{(1) Coding}

Linguist weights can be represented by integer 0 , $1,2, . ., t$ respectively, if the total number of items is $m$, then the length of gene can be $2 \times m$.

For example, "41233" is a gene coded for linguistic weights in the technical examination of vehicles, which represents the linguistic weight "Very high", “Low”, “Medium”, "High” and "High" respectively.

(2) The scale $M$ of the initial group

As the starting point for the Genetic Algorithm, the initial group should be with a proper scale $M$. The bigger the scale $M$ is, the wider the range of searching, and the longer the time taken for regeneration. On the contrary, the smaller the scale $M$ is, the narrower the range of searching and the shorter the time taken for regeneration. Generally scale $M$ is set to be more than 50 and less than 100 . In this paper, it is set to be 80 , and the initial group of gene is generated randomly.

(3) The Crossover Probability $p_{c}$

As a main method to generate the new genes for the Genetic Algorithm, the Crossover operator should be set a proper Crossover Probability $p_{c}$. In this paper we choose the single point crossover operator, and The Crossover Probability $p_{c}$ is set to be 0.60 .

\section{(4) The Mutation Probability $p_{m}$}

Mutation is another method to generate the new genes in Genetic Algorithm, which leads to the variety of species. The bigger the Mutation Probability $p_{m}$ is, the bigger the possibility for generating the new genes is. But the good genes will be destroyed when the Mutation Probability $p_{m}$ is too big, which may let the performance of Genetic Algorithm act as random. In this paper, we set the Mutation Probability $p_{m}$ to be 0.005 .

(5) The total number of generations $T$

In this paper, the total number of generations $T$ is set to be 700 .

\section{Illustrative example}

In the technical examination of vehicles, the set of linguistic values for the result of each examination item can be defined as 
$S=\left\{S_{0}=\right.$ Extremely poor, $S_{1}=$ Very poor, $s_{2}=$ Poor, $s_{3}=$ Medium, $s_{4}=$ Good, $s_{5}=$ Very good, $s_{6}=$ Extremely good $\}$.

Also, the attributes' weight value can be defined as $S^{\prime}=\left\{\quad s_{0}^{\prime}=\right.$ Very low, $s_{1}^{\prime}=$ Low, $s_{2}^{\prime}=$ Medium, $s_{3}^{\prime}=$ High, $s_{4}^{\prime}=$ Very high $\}$.

Evaluators give the subjective weights

$$
\begin{aligned}
\left(w_{1}, w_{2},\right. & \left.w_{3}, w_{4}, w_{5}, w_{6}\right) . \\
= & \left(s_{1}^{\prime}, s_{1}^{\prime}, s_{2}^{\prime}, s_{1}^{\prime}, s_{1}^{\prime}, s_{3}^{\prime}\right)
\end{aligned}
$$

There are twenty cases about the energy supply device of the HONDA ACCORD 7230 hydraulic brake system, and the examination items are "Pedal and Master Pump Push Rod", "Pedal Free Trip", "Pedal Effective Trip", "Booster Trachea Vacuum Degree", "Booster Function" and "Booster Pipeline and Joints". The evaluations for each item and final results are all expressed in linguistics values, as shown in table 3.

\begin{tabular}{|l|l|l|l|l|}
\hline $\begin{array}{c}\text { Case } \\
\text { No. }\end{array}$ & $\begin{array}{c}\text { Pedal and } \\
\text { Master Pump } \\
\text { Push Rod }\end{array}$ & $\cdots$ & $\begin{array}{c}\text { Booster } \\
\text { Pipeline and } \\
\text { Joints }\end{array}$ & \multicolumn{1}{|c|}{$\begin{array}{c}\text { Final } \\
\text { Results }\end{array}$} \\
\hline 1 & $S_{2}$ & & $S_{2}$ & $S_{2}$ \\
\hline 2 & $S_{1}$ & & $S_{3}$ & $S_{3}$ \\
\hline 3 & $S_{3}$ & & $S_{4}$ & $S_{3}$ \\
\hline$\cdot$ & & & & \\
$\cdot$ & & & & $S_{3}$ \\
\hline 19 & $S_{3}$ & & $S_{2}$ & $S_{2}$ \\
\hline 20 & $S_{2}$ & & $S_{2}$ & \\
\hline
\end{tabular}

Table 3: The evaluations for each item and final results.

We set a weights optimization model, and $\lambda$ is set to be 0.5 , the discrepancy between subjective weights and optimization weights are defined in table 4.

\begin{tabular}{|c|c|c|c|c|c|}
\hline & $\begin{array}{c}\text { Very } \\
\text { low }\end{array}$ & $\begin{array}{c}\text { Very } \\
\text { low }\end{array}$ & Medium & High & $\begin{array}{c}\text { Very } \\
\text { high }\end{array}$ \\
\hline Very low & 0 & 20 & 40 & 80 & 160 \\
\hline low & 20 & 0 & 20 & 40 & 80 \\
\hline Medium & 40 & 20 & 0 & 20 & 40 \\
\hline High & 80 & 40 & 20 & 0 & 20 \\
\hline $\begin{array}{c}\text { Very } \\
\text { high }\end{array}$ & 160 & 80 & 40 & 20 & 0 \\
\hline
\end{tabular}

Table 4: the discrepancy between subjective weights and optimization weights.
By applying the Genetic Algorithm to solve this model, we get the final optimization weights $\left(w_{1}, w_{2}, w_{3}, w_{4}, w_{5}, w_{6}\right)=\left(s_{1}^{\prime}, s_{1}^{\prime}, s_{1}^{\prime}, s_{1}^{\prime}, s_{1}^{\prime}, s_{2}^{\prime}\right)$, and the total discrepancy is 110 . We collect another 20 cases to verify the method, and through the optimization weights and the objective weighs the final results of these cases are aggregated respectively. Comparing with the evaluation results given by evaluators, we get the table 5 .

\begin{tabular}{|c|c|c|c|}
\hline & $\begin{array}{c}\text { The } \\
\text { Correct } \\
\text { rate }\end{array}$ & $\begin{array}{c}\text { Total } \\
\text { Discrepancy }\end{array}$ & $\begin{array}{c}\text { Average } \\
\text { Discrepancy }\end{array}$ \\
\hline $\begin{array}{c}\text { By objective } \\
\text { weighs }\end{array}$ & $70 \%$ & 410 & 20.5 \\
\hline $\begin{array}{c}\text { By } \\
\text { optimization } \\
\text { weighs }\end{array}$ & $85 \%$ & 120 & 6 \\
\hline
\end{tabular}

Table 5: Result comparing between objective weighs and optimization weighs.

\section{Conclusions}

A multi-attribute evaluation method is put forward in this paper, in which the attributes' weights and the attributes' values are all expressed in the form of linguistic values. Based on this form the final result can be aggregated by the LIA, which was also defined in this paper. To get the objective linguistic weights, a linguistic weights optimization model, with the minimum total discrepancy as its target, is advanced. The Genetic Algorithm is applied to solve this model, so we get the final optimizes linguistics weights.

Taking the examination of energy supply device as the example, 20 cases with the evaluation records of evaluators are applied in the model to get the optimization linguistic weights, and after aggregating another 20 cases, it turns out that the optimization linguistic weights is effective

The fact shows it is feasible to make multiattribute evaluation with linguistic values. However, the problems such as what is the most proper form of linguistic values to represent the attributes' weights and attributes' values, and what is the most effective linguistic aggregation operation, need to be further studied. In this paper, we define the operation rules according to the evaluators' subjective experience, and we express the discrepancy with some numeric values, which need to be studied as well.

From table 5 we know that the optimization weights method is better than the subjective weights method because it's more accurate.

\section{Acknowledgement}


This paper is partially supported by the National Natural Science Foundation of China (Grant no. 60474022), the specialized Research Fund for the Doctoral Program of Higher Education of China under Grant No. 20060613007, and the Youth Found of Education Office in Sichuan Province, P.R. China (Grant no. 2006B044).

\section{References}

[1] M.J. Zaki, K. Gouda, Fast verticalmining using diffsets. In Proc. Of ACM SIGKDD'03, Washington, DC, 2003.

[2] M. Delgado, J.L. Verdegay and M.A. Vila, On aggregation operations of linguistic label. International Journal of Intelligent Systems, 8 (4):351-370, 1993.

[3] G. Bordogna, M. Fedrizzi and G. Pasi, A linguistic modeling of consensus in group decision making based on OWA operators. IEEE Transaction on Systems, Man and Cybernetics Part A: Systems and Humans, 27(1): 126-132, 1997.

[4] J. Kacpizyk, Group decision making with a fuzzy linguistic. Fuzzy Sets and Systems, 18(1): 105-118, 1986.

[5] F. Herrera, E. Herrera-Viedma and J.L. Verdegay, A sequential selection process in group decision-making with linguistic assessments. Information Sciences, 85(3): 223229, 1995.

[6] F. Herrera, E. Herrera-Viedma and J.L. Verdegay, A linguistic decision process in group decision making. Group Decision Negotiation, 5(2): 165-176, 1996.

[7] F. Herrera, E. Herrera-Viedma and J.L. Verdegay, A rational consensus model in group decision making using linguistic assessment. Fuzzy Sets and Systems, 88(1): 31- 49, 1997.

[8] H.Y. Li, Z.P. Fan, Multi-criteria Group Decision Making Method Based on Two-tuple Linguistic Information Processing. Journal of Northeastern University(Natural Science), 24(5): 495 - 498, 2003.

[9] F. Herrera, E. Herrera-Viedma and J.L. Verdegay, A model of consensus in group decision making under linguistic assessments. Fuzzy Sets and Systems, 78: 73-87, 1996.

[10] F. Herrera, E. Herrera-Viedma and J.L. Verdegay, Direct approach processes in-group decision-making using linguistic OWA operators. Fuzzy Sets and Systems, 79:175-190, 1996.

[11] T.H. You, Z.P. Fan, TOPSIS Method for Multiple Attribute Decision Making with Intervals. Journal of Northeastern
University(Natural Science), 23(9): 840-843, 2002.

[12] Z.S. Xu, A multi-attribute group decision making method based on term indices in linguistic evaluation scales. Journal of Systems Engineering, 20(1): 84-88, 2005.

[13] Z.S. Xu, Q.L. Da, An overview of operators for aggregating information. Int. $J$. Intelligent Systems, 18: 953-969, 2003.

[14] Z.S. Xu, Extended IOWG Operator and its Use in Group Decision Making Based on Multiplicative Linguistic Preference Relations American. Journal of Applied Sciences, 2(3): 633-643, 2005.

[15] Z.S. Xu, A Priority Method Based on Induced Ordered Weighted Averaging (IOWA) Operator for Fuzzy Linguistic Preference Matrices. Systems Engineering and Electronics, 25(4): 440-443, 2003.

[16] Z.S. Xu, Method based on fuzzy linguistic assessments and giowa operator in multiattribute group decision-making. Journal of Systems Science and Mathematical Sciences, 24(2): 218-224, 2004.

[17] X.R. Wang, Z.P. Fan, A TOPSIS Method with Linguistic Information for Group Decision Making. Chinese Journal of Management Science, 10(6):84-87, 2002.

[18] Y.P. Jiang, Z.P. Fan, An Approach to Group Decision-Making Problems Based on Two-Tuple Linguistic Symbol Operation. Systems Engineering and Electronics, 25(11): 1373-1376, 2003.

[19] Z.S. Xu, A Method Based on Fuzzy Linguistic Assessments and Linguistic Ordered Weighted Averaging(OWA) Operator for Multi-Attribute Group Decision-Making Problems. Systems Engineering, 20(5): 79-82, 2002.

[20] Z.S. $\mathrm{Xu}$, On method of multi-attribute group decision making under pure linguistic information. Control and Decision, 19(1): 778782, 2004.

[21] S.L. Liu, Wanhua Qiu, Studies on the Basic Theories for MADM. Systems EngineeringTheory \& Practice, 18(1): 38- 43, 1998.

[22] Z.S. Xu, Q.L. Da, The hybrid linguistic weighted averaging operator. International Journal of Intelligent Systems, 18(3): 117-120, 2005.

[23] F. Herrera, E. Herrera-Viedma, Aggregation Operators for Linguistic Weighted Information. IEEE Transactions on Systems, Man and Cybernetics, 27: 646-656, 1997.

[24] X.R. Wang, Z.P. Fan, Approach to multiple attribute group decision making with linguistic 
assessment information. Journal of Systems Engineering, 18(2): 173-176, 2003.

[25] Yan Chen, Zhiping Fan, TOPSIS method for group decision-making based on linguistic assessment information. Journal of Nanjing University, 26(3): 27-30, 2004.

[26] Yager R R, On ordered weighted averaging aggregation operators in multicriteria decision making. IEEE Transactionson Systems Man and Cybernetics, 18: 183 - 190, 1988.

[27] Herrera F, Verdegay J L, linguistic assessment in group decision. Proc 1st European Congress on Fuzzy and Intelligent Technologies, Aachen, pp. 941-948, 1993.

[28] Delgado M, Verdegay J L and Vila M A, On aggregation operations of linguistic label. International Journal of Intelligent Systems, 8: 351-370, 1993

[29] Yang Xu, Xianyi Zeng and Ludovic Koehl, An intelligent sensory evaluation method for industrial products characterization. International Journal of Information Technology \& Decision Making, 6(2): 349-370, 2007. 